\title{
Design, Synthesis, and Photophysical Properties of BODIPY-Labeled Lupane Triterpenoids ${ }^{\dagger}$
}

\author{
Rinat Gubaidullin, Darya Nedopekina, Adis Tukhbatullin, Eldar Davletshin and Anna Spivak*
}

Citation: Gubaidullin, R.;

Nedopekina, D.; Tukhbatullin, A.; Davletshin, E.; Spivak, A. Design, Synthesis, and Photophysical Properties of BODIPY-Labeled Lupane Triterpenoids. Chem. Proc. 2021, 3, 11. https://doi.org/10.3390/ ecsoc-24-08102

Academic Editors: Julio A. Seijas and M. Pilar Vázquez-Tato

Published: 13 November 2020

Publisher's Note: MDPI stays neutral with regard to jurisdictional claims in published maps and institutional affiliations.

Copyright: (C) 2020 by the authors. Licensee MDPI, Basel, Switzerland. This article is an open access article distributed under the terms and conditions of the Creative Commons Attribution (CC BY) license (http://creativecommons.org/licenses/by/4.0/).

\author{
Institute of Petrochemistry and Catalysis of Russian Academy of Sciences, 141 Prospekt Oktyabrya, \\ 450075 Ufa, Russia; rinatg83@mail.ru (R.G.); rawbe2007@mail.ru (D.N.); adis0501@mail.ru (A.T.); \\ eldarik1996@mail.ru (E.D.) \\ * Correspondence: spivak.ink@gmail.com; Tel.: +79174217106 \\ + Presented at the 24th International Electronic Conference on Synthetic Organic Chemistry, 15 November-15 \\ December 2020; Available online: https://ecsoc-24.sciforum.net/.
}

\begin{abstract}
Novel boron-dipyrromethene difluoride (4,4-difluoro-4-bora-3 $\alpha, 4 \alpha$-diaza-s-indacene) (BODIPY)-lupane triterpenoid conjugates bearing a fluorescent marker at the C-2 position of ring A of the triterpene core were obtained via the Sonogashira reaction as a key step. The starting compounds in the cross-coupling reaction were C-2 propynyl derivatives of betulinic or betulonic acids and fluorescent dyes with an iodo-group at C-2 or meso position of BODIPY-platform. The newly elaborated coupling procedure might have applicability in the synthesis of fluorescently-labeled triterpenoid conjugates suitable for biological assays.
\end{abstract}

Keywords: pentacyclic triterpenoids; betulinic acid; BODIPY; fluorescent derivatives; Sonogashira coupling

\section{Introduction}

Pentacyclic triterpenic acids, including the lupane family of triterpenoids (betulin, betulinic, and betulonic acids), are an important class of natural plant products. The widespread availability in nature, beneficial biological and pharmacological properties (antitumor, antiviral, and antiparasitic effects), and easy transformation of native 3-OH and 17-COOH groups make these secondary plant metabolites promising scaffolds for the discovery of new drug candidates [1-3]. To date, the derivatization of the C-3 hydroxyl and C-17 carboxyl functions in natural triterpenic acids has been applied to obtain numerous semi-synthetic derivatives, which in some cases have surpassed the parent compounds in their biological action and pharmacological parameters [4,5]. Thus, some derivatives of betulinic acid with $\mathrm{C}-3$ and/or C-17 side chains, including 3-O-(3',3'-dimethylsuccinyl)betulinic acid, known as beverimate, exhibited a high inhibitory effect against HIV-1 human immunodeficiency virus [6-9]. The addition of lipophilic mitochondria-targeted cationic groups to the triterpene skeleton significantly increased the cytotoxicity of triterpenoids. The resulting cationic derivatives of triterpene acids exhibited antitumor activity at low micromolar or even nanomolar concentrations [10-17]. There are works detailing some aspects of the mechanism of antiviral or antitumor action of the identified lead compounds of the triterpene structure $[10,14,15,17]$. Studies detailing molecular and cellular events involving these compounds have not yet been reported.

Over the last few years, fluorescently-labeled probes of small bioactive molecules have provided powerful means for studying biological phenomena and the mechanism of action of these molecules. Fluorescent labeling technologies offer a good opportunity to analyze the interaction of drugs with molecular targets at the cellular, subcellular levels, as well as in vivo at the level of the whole organism. Meanwhile, among the series of low molecular weight fluorescent compounds used for labeling biologically active 
molecules and analysis of biological phenomena, the BODIPY family fluorophores are in wide demand $[18,19]$. The fluorophore, boron-dipyrromethene difluoride (4,4-difluoro-4bora-3 $\alpha, 4 \alpha$-diaza-s-indacene), known under the BODIPY trademark, stand out with its many attractive spectral properties such as high absorption coefficient, high fluorescence (FL) quantum yield, photochemical stability, stability in a physiological environment, good solubility in organic solvents, and great potential for structural derivatization $[19,20]$. The BODIPY family fluorophores have been covalently linked to numerous classes of biomolecules, including proteins [20,21], carbohydrates [22], fatty acids, and steroids [23-28]. Still, only two research papers on the synthesis and fluorescent biological analysis of BODIPY-labeling of triterpenoid compounds have been reported so far [29,30]. In these works, fluorescent pentacyclic triterpene conjugates have been prepared by covalent binding to the known (BODIPY-FL) BODIPY-propanoic acid fluorophore through the $3-\mathrm{OH}$ and $17-\mathrm{COOH}$ functional groups. Unfortunately, this resulted in a decrease or even a complete loss of the cytotoxic effect of the new compounds compared to the parent compounds. The research results are consistent with the already well-known facts about the key role of the C-3 and C-17 functional groups of triterpenoids as pharmacophores [4,5].

Here we aimed to work out a new approach for the synthesis of BODIPY-triterpenoid acids conjugates avoiding covalent binding of the triterpene core to the BODIPY-platform at the C-3 and C-17 positions. We have recently developed an efficient method for introducing a propynyl substituent at the C-2 position of the ring A of triterpenic acids and demonstrated that the terminal acetylene moiety in these compounds could be effectively involved in the CuAAC reaction and in the Sonogashira coupling reaction [31-33]. In this research project, we applied C-2 propynyl derivatives of betulinic and betulonic acids 35 as initial substances for conjugation with some BODIPY dyes through the Sonogashira coupling reaction.

\section{Materials and Methods}

\subsection{Chemistry}

The starting compounds betulin, betulinic acid, and reagents: $\mathrm{BEt}_{3}(95 \%), \mathrm{KN}\left(\mathrm{SiMe}_{3}\right)_{2}$ ( $1 \mathrm{M}$ solution in THF), $\mathrm{CeCl}_{3} .7 \mathrm{H}_{2} \mathrm{O}$, and $\mathrm{NaBH}_{4}$ were purchased from Aldrich and used without any further purification. Propargyl bromide, $\mathrm{LiI}, \mathrm{CH}_{3} \mathrm{COCl}, \mathrm{CuI}, \mathrm{PdCl}_{2}\left(\mathrm{PPh}_{3}\right)_{2}$, $\mathrm{Et}_{3} \mathrm{~N}, \mathrm{DME}$ (dimethoxyethane) 2,4-dimethylpyrrole, pyrrole, 4-iodobenzaldehyde, boron trifluoride etherate, iodine monochloride, indium(III) chloride, DDQ were purchased from Acros organics and used without any further purification. Betulonic acid was obtained from betulin according to known procedures. [34] The starting compounds 17-20 were prepared according to known procedures. [35-37]

\section{General Procedure for the Synthesis of Methyl Betulonate Adducts with BODIPY 21-26}

A mixture of corresponding triterpenoid $(0.18 \mathrm{mmol})$, corresponding BODIPY $(0.16$ mmol) were dissolved in anhydrous Et ${ }_{3} \mathrm{~N} / \mathrm{DMF}(5 \mathrm{~mL}, 1.5: 1)$. Then CuI $(6.1 \mathrm{mg}, 0.03$ $\mathrm{mmol})$ and $\mathrm{PdCl}_{2}\left(\mathrm{PPh}_{3}\right)_{2}(7.0 \mathrm{mg}, 0.01 \mathrm{mmol})$ were added to the mixture simultaneously, and the resulting mixture was stirred at room temperature for 1-3 $\mathrm{h}$ under an argon atmosphere. The completion of the reaction was monitored by TLC analysis. The reaction was quenched by the addition of water and extracted with EtOAc $(3 \times 10 \mathrm{~mL})$. The combined organic extracts were dried with $\mathrm{MgSO}_{4}$ and concentrated under reduced pressure. The residue was purified by column chromatography on silica gel with hexane/EtOAc (from 25:1 to 10:1) as an eluent to afford pure products 21-26.

\section{Results and Discussion}

Compounds 3-5 were synthesized through $\alpha$-alkylation with propargyl bromide of potassium enoxytriethylborates, generated by treating betulonic acid methyl ester 2 with the $\mathrm{KN}\left(\mathrm{SiMe}_{3}\right)_{2}-\mathrm{Et}_{3} \mathrm{~B}$ reagent. Methyl betulonate 2 was obtained by oxidation of commercially available betulin 1 (Scheme 1). The derived triterpenoids 3-5 were linked to the 
BODIPY-core by a chemically stable carbon-carbon bond through propynyl or phenylpropynyl linkers. To accomplish this, we synthesized photostable meso-aryl-substituted BODIPY 15-20 as starting compounds from commercially available pyrrole, 2,4-dimethylpyrrole, and 4-Br, 4-Me, and 4-I benzaldehydes.
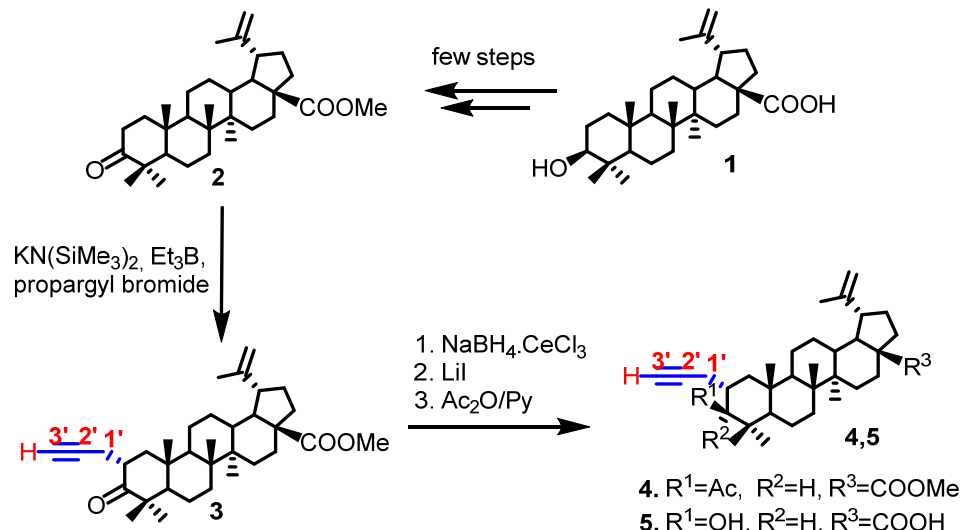

Scheme 1. Synthesis of C-2 propynyl derivatives of betulonic and betulinic acids 3-5 [31].

BODIPY iodine derivatives containing an iodine atom in the phenyl ring 17,18 were linked directly to triterpenoids 3-5, while meso-aryl-substituted BODIPY 15, 16 containing an electron-donor $(\mathrm{Me})$ or electron-withdrawing $(\mathrm{Br})$ substituent in the aryl group were subjected to iodination to obtain the target monoiodo-BODIPY derivatives at the two-position 19, 20 (Scheme 2).

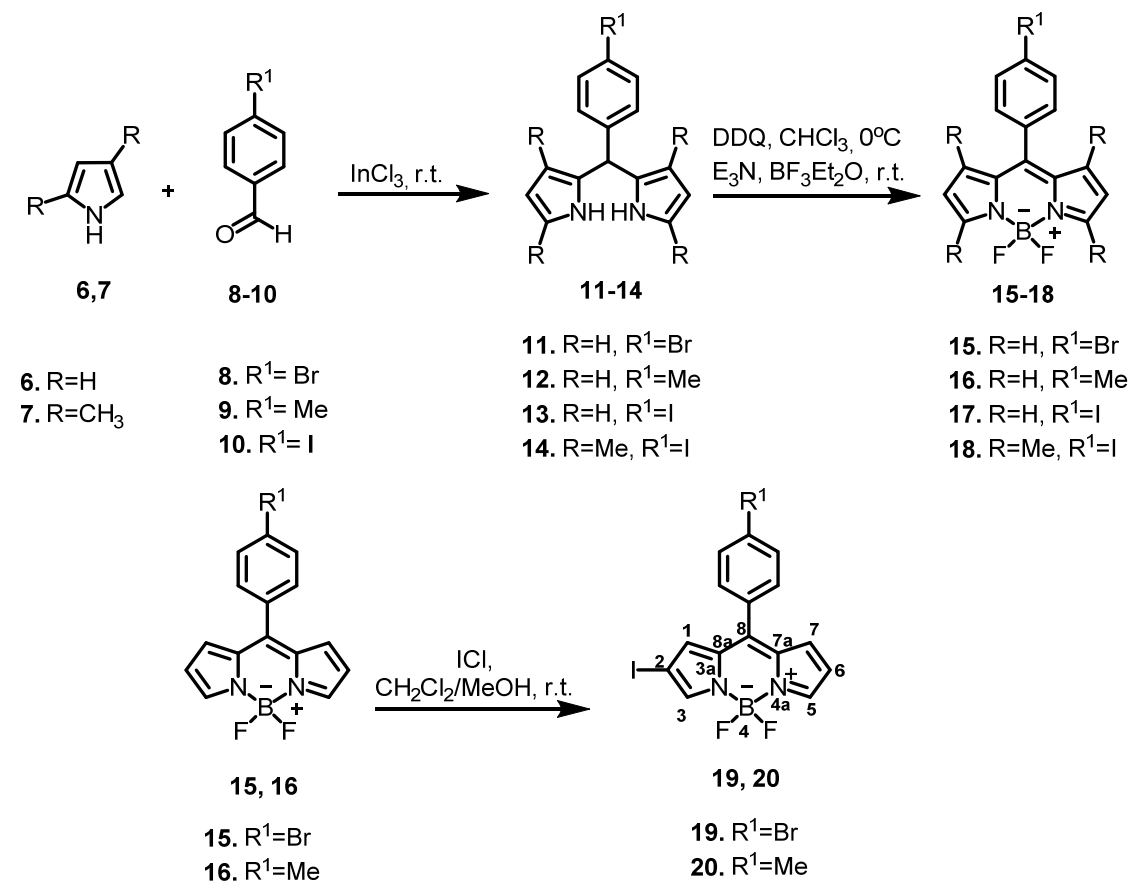

Scheme 2. Synthesis of meso-aryl-substituted derivatives boron-dipyrromethene difluoride $(4,4-$ difluoro-4-bora-3 $\alpha, 4 \alpha$-diaza-s-indacene) (BODIPY) 15-20.

Syntheses of meso-aryl-substituted BODIPY were carried out by a classical three-step method, starting with condensation of pyrrole rings with aryl aldehydes. In these reactions, trifluoroacetic acid or $\mathrm{BF}_{3} \cdot \mathrm{OEt}_{2}$ is traditionally involved as acid catalysts protonating or chelating the carbonyl oxygen atom, and the reactions are carried out in $\mathrm{CH}_{2} \mathrm{Cl}_{2}$ [19]. We synthesized dipyrromethanes 11-14 by the method [35] with $\mathrm{InCl}_{3}$ as an acid catalyst. 
The reactions were carried out at a large (20 molar) excess of the pyrrole or dimethylpyrrole, serving as a reagent and solvent at once. These conditions offered a significant reduction in the formation of pyrrole oligomerization by-products and preparation of the target dipyrromethanes 11-14 in high yields (67-87\%). Oxidation of dipyrromethanes by 2,3-dichloro-5,6-dicyano-p-benzoquinone (DDQ) gave dipyrromethenes which were reacted with a 16-fold excess of $\mathrm{BF}_{3} \cdot \mathrm{OEt}_{2}$ without isolation and purification under typical conditions involving $\mathrm{Et}_{3} \mathrm{~N}$ [36]. Two-step one-pot synthesis helped to achieve target BODIPY derivatives 15-18 in 28-67\% yields (Scheme 2). The oxidation and complexation reactions of dipyrromethane $\mathbf{1 4}$ were considerably complicated by the formation of oligomerization products; thorough chromatographic purification of the reaction mixture on silica gel gave fluorophore $\mathbf{1 8}$ in a relatively low yield (28\%).

The record shows that the introduction of halogens, usually Br or I atoms, at positions two and six or three and five of the BODIPY platform bring about a bathochromic shift in the absorption and emission spectra and FL quenching as compared to parent dyes [37]. The products of halogenation of pyrrole fragments at these positions are usually further applied to implement Pd-catalyzed coupling reactions, including Sonogashira coupling [37-42]. The analysis of the mesomeric structures of BODIPY revealed that the two- and six-positions have a small positive charge compared to other carbon atoms of the pyrrole fragments. Therefore, these positions can be most susceptible to electrophilic attacks. The study [37] illustrated that iodination of a BODIPY dye with unsubstituted pyrrole rings using $\mathrm{ICl}$ in an equimolar ratio gives the C-2 monoiodo derivative of BODIPY in a relatively high yield and selectivity. In our study, iodination of meso-substituted derivatives of BODIPY 15, 16 according to the method [37] at an equimolar ratio of fluorophores and $\mathrm{ICl}$ in a mixture of solvents $\mathrm{CH}_{2} \mathrm{Cl}_{2} / \mathrm{MeOH}$ produced the target iodides 19, 20 after their purification by column chromatography on silica gel in 76 and $77 \%$ yields, respectively.

The synthesis of BODIPY-triterpenoid 21-26 conjugates linked through propynyl or phenylpropynyl bridges at the meso position of the dye or at the C-2 position of the BODIPY platform was carried out by cross-coupling according to the Sonogashira reaction. The reaction proceeded for 1-3 $\mathrm{h}$ at room temperature in $\mathrm{Et}_{3} \mathrm{~N} / \mathrm{DMF}$ (1.5:1) medium under the action of $\mathrm{PdCl}_{2}\left(\mathrm{PPh}_{3}\right)_{2}$ and $\mathrm{CuI}$ catalysts. The yields of target products 21-26 were 53$88 \%$ after a silica gel column chromatography (Scheme 3). It should be pointed out that the propynyl derivative of betulonic acid $\mathbf{3}$ was not involved in the cross-coupling reaction with the meso-(4-bromophenyl) substituted derivative BODIPY 15 . Under the above conditions, dimerization of the methyl ester of betulonic acid was registered; the target product could not be observed even in trace amounts (Scheme 3).

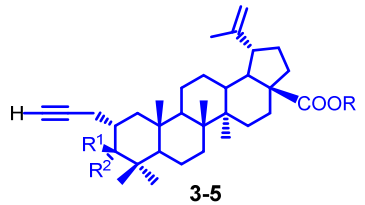

3. $R=M e, R^{1}+R^{2}=O$

4. $R=M e, R^{1}=A c, R^{2}=H$

5. $\mathrm{R}=\mathrm{H}, \mathrm{R}^{1}=\mathrm{OH}, \mathrm{R}^{2}=\mathrm{H}$

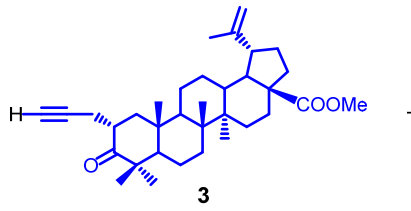

3. $R=M e, R^{1}+R^{2}=O$

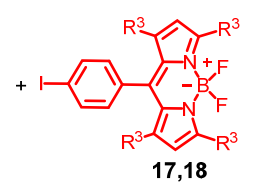

17. $\mathrm{R}^{3}=\mathrm{H}$

18. $R^{3}=\mathrm{Me}$

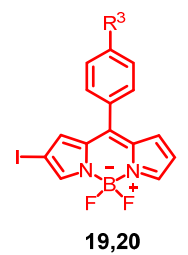

19. $\mathrm{R}^{3}=\mathrm{Br}$ 20. $R^{3}=M e$

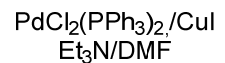

$\mathrm{PdCl}_{2}\left(\mathrm{PPh}_{3}\right)_{2} / \mathrm{Cul}$ $\mathrm{Et}_{3} \mathrm{~N} / \mathrm{DMF}$

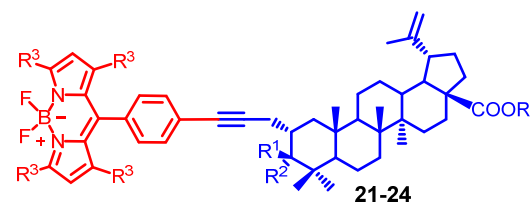

21. $R=M e, R^{1}+R^{2}=O, R^{3}=H$ 22. $R=M e, R^{1}+R_{2}=O, R^{3}=M e$ 23. $R=M e, R^{1}=A c, R^{2}=H, R^{3}=H$

24. $\mathrm{R}=\mathrm{H}, \mathrm{R}_{1}=\mathrm{OH}, \mathrm{R}^{2}=\mathrm{H}, \mathrm{R}^{3}=\mathrm{H}$

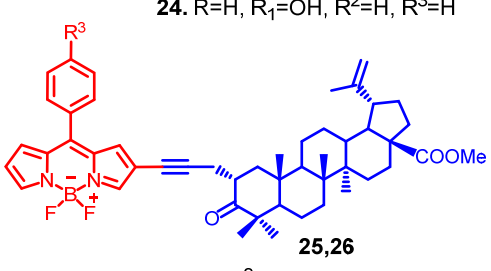

25. $\mathrm{R}^{3}=\mathrm{Br}$ 26. $R^{3}=\mathrm{Me}$

Scheme 3. Synthesis of BODIPY-triterpenoid conjugates 21-26 via Sonogashira coupling. 
The compounds 21-26 were studied by various spectroscopic techniques. The molecular ion peak in mass spectra and matching elemental analysis with the expected composition of compounds confirmed the identity of the compounds 21-26. The NMR spectra data of compounds 21-26 slightly differed. As such, an extensive analysis of the NMR spectrum for compound $\mathbf{2 1}$ is presented here. Thus, the signals of the carbon atoms of the acetylene bond C-2' and C-3' were observed to shift downfield (to 92.1 and 80.9 ppm, respectively) in the ${ }_{13} \mathrm{C}$ NMR spectrum of compound 21, compared to the original propynyl derivative 3 (82.8 and 69.1 ppm, respectively). Moreover, a signal of a quaternary carbon atom in the region of 126.9 ppm was registered in the ${ }_{13} \mathrm{C}$ NMR spectrum, which we identified as the carbon atom bonded to the acetylene fragment. The ${ }_{1} \mathrm{H}$ NMR spectrum of compound 21 revealed the presence of a new multiplet signal in the region of 7.54 ppm, belonging to the signals of the phenyl substituent, as well as the presence of signals of pyrrole protons in the region of $6.94\left(\mathrm{H}-1^{\prime \prime}\right), 6.56\left(\mathrm{H}-2^{\prime \prime}\right), 7.96\left(\mathrm{H}-3^{\prime \prime}\right)$ ppm. The collected spectral data conclude that there is a covalent bond in the structure of compound 21 between the carbon of the phenyl substituent BODIPY and the carbon of the acetylene fragment of the triterpene framework and, consequently, the involvement of functional groups in the Sonogashira cross-coupling reaction.

In fact, the aryl substituent in the meso position of the BODIPY fluorophores is located almost perpendicular to the BODIPY nucleus. Therefore, it participates little in electronic conjugation and does not have a significant impact on the change in the absorption and emission wavelengths of the dye. At the same time, the introduction of $\pi$-electron donors such as phenylethynyl or ethynyl groups in the 2,6- or 3,5-position of the BODIPY skeleton can noticeably increase the absorption and emission wavelengths compared to the unsubstituted BODIPY molecule [41,42]. In this regard, we decided to investigate the spectroscopic properties of the fluorescent conjugates of tritepenoid-BODIPY 21-24 in comparison with conjugates $25,26$.

The spectroscopic properties of BODIPY-fluorophores 17-20 and conjugates 21-26 were studied in $\mathrm{MeOH}$. The findings of this study are summarized in Table 1 and Figure 1 (absorption and photoluminescence (PL) spectra of compounds 17-26 in MeOH). The form of the absorption and emission spectra of BODIPY-derivatives 17-20 corresponds to the previously reported similar compounds [37,38,41]. Characteristic maxima with a rather high molar extinction coefficients and small Stokes shifts are recorded in the absorption and PL spectra of these compounds. The iodine substituent at the C-2 atom of the BODIPY core caused a significant red-shift of the absorption and emission maxima, while quenching of the quantum yield was observed.

Table 1. Spectral and luminescent properties of compounds 17-26 at T = 297 K in MeOH.

\begin{tabular}{|c|c|c|c|c|c|c|}
\hline Entry & Solvent & $\begin{array}{c}\mathrm{Abs}^{1} \\
\lambda \max , \mathrm{nm}\end{array}$ & $\begin{array}{c}\varepsilon \times 104 \\
M^{-1} \cdot \mathrm{cm}^{-1}\end{array}$ & $\begin{array}{c}\text { FL } \\
\lambda \max , \mathrm{nm}\end{array}$ & $\varphi$ & $\begin{array}{c}\text { Stokes Shift } \\
\text { nm }\end{array}$ \\
\hline 17 & $\mathrm{MeOH}$ & 500 & 6.8 & 518 & 0.01 & 18 \\
\hline 18 & $\mathrm{MeOH}$ & 500 & 9.3 & 509 & 0.41 & 9 \\
\hline \multirow{2}{*}{19} & \multirow{2}{*}{$\mathrm{MeOH}$} & 503 & 4.2 & 522 & 0.01 & 19 \\
\hline & & 519 & 4.1 & 548 & & 29 \\
\hline 20 & $\mathrm{MeOH}$ & 517 & 5.9 & 544 & 0.01 & 27 \\
\hline 21 & $\mathrm{MeOH}$ & 499 & 4.2 & 519 & 0.01 & 20 \\
\hline 22 & $\mathrm{MeOH}$ & 498 & 6.5 & 509 & 0.38 & 11 \\
\hline 23 & $\mathrm{MeOH}$ & 500 & 3.6 & 517 & 0.01 & 17 \\
\hline 24 & $\mathrm{MeOH}$ & 500 & 4.6 & 518 & 0.01 & 18 \\
\hline 25 & $\mathrm{MeOH}$ & 539 & 4.7 & 582 & 0.06 & 43 \\
\hline 26 & $\mathrm{MeOH}$ & 534 & 2.4 & 571 & 0.14 & 37 \\
\hline
\end{tabular}


Conjugation of the triterpenoid core to BODIPY at the C-8 atom of the dye through the phenylethynyl spacer in compounds 21-24 did not change the position of the absorption and PL maxima in comparison with the initial fluorophores (for example, compounds 17 and 21).

The presence of methyl substituents in the pyrrolic fragments of BODIPY 18 and its conjugate with triterpenoid $\mathbf{2 2}$ considerably increased the quantum yield and caused a slight hypsochromic shift of the PL maximum in comparison to unsubstituted analogs $\mathbf{1 7}$ and 21. Attachment of the triterpenoid 2 to BODIPY moiety at C-2 position via propynyl spacer produced a noticeable bathochromic shift in the absorption maximum in conjugates 25 and 26 (Table 1 and Figure 1c,d). The luminescence of conjugates 25 and 26 (570$580 \mathrm{~nm}$ ) also shifted to the long-wavelength region of the spectrum relative to unsubstituted BODIPY $(518 \mathrm{~nm})$. Furthermore, compared to the initial iodine derivatives BODIPY 19 and 20, a noticeable increase in the quantum yield and Stokes shifts were observed in conjugates 25 and 26.

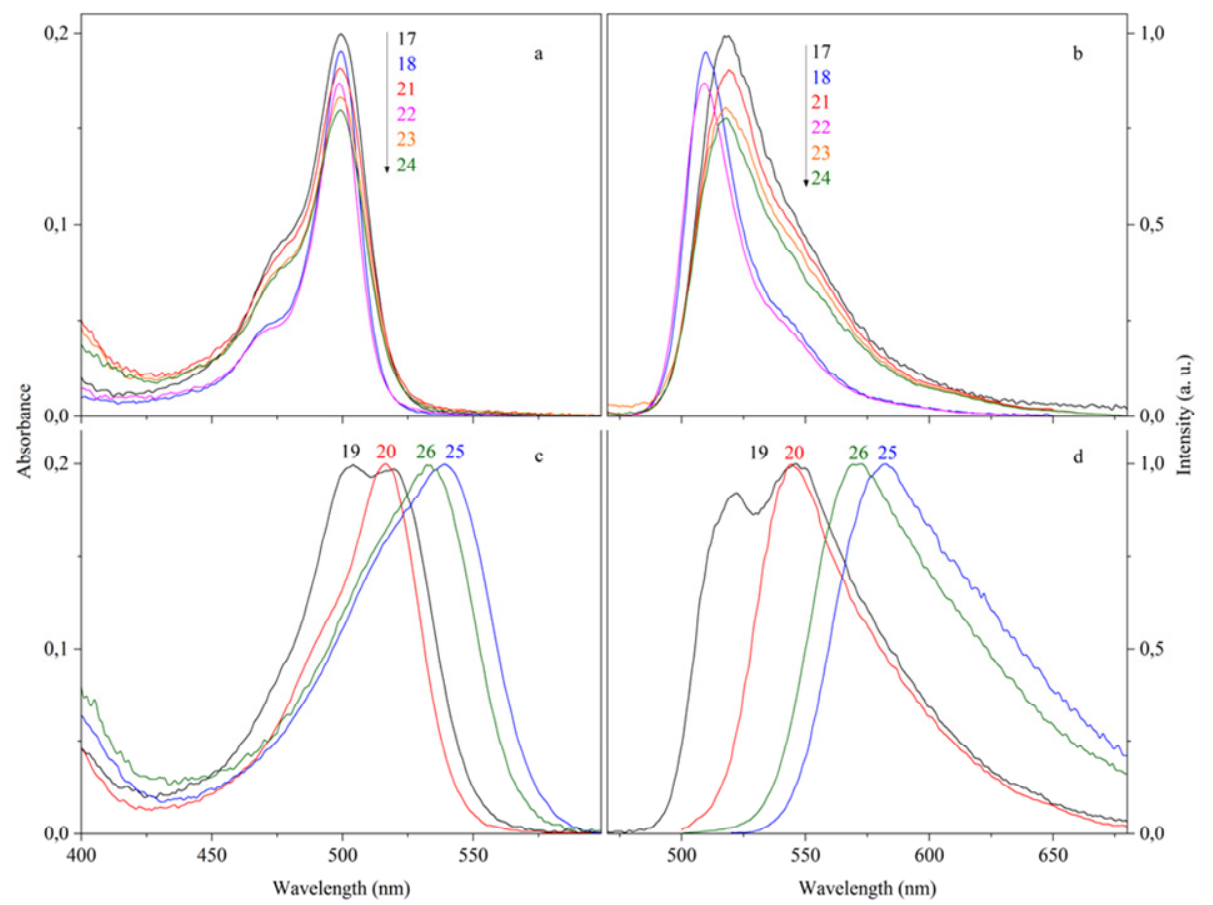

Figure 1. Absorption spectra (a,c) and photoluminescence (PL) (b,d) of the target BODIPY derivatives 17-20 and BODIPY triterpenoid conjugates 21-26. $\mathrm{T}=298 \mathrm{~K}, \mathrm{C}=10^{-6} \mathrm{~mol} \cdot \mathrm{l}^{-1}$ in $\mathrm{MeOH}, \lambda$ exc $=$ $350 \mathrm{~nm}$, Fluorolog-3, $\Delta \lambda=1 \mathrm{~nm}$.

\section{Conclusions}

In this article, an efficient synthesis has been developed, and six new fluorescent conjugates of lupane triterpenoids were synthesized, with the triterpene core linked to the BODIPY fluorophore at the C-8 or C-2 positions of the dye through propynyl or phenylpropynyl spacers. The study of the fluorescent properties of the resulting conjugates revealed that the conjugates (compounds 21-24) retained the fluorescent properties of the initial chromophores upon covalent binding of terpenoids to the BODIPY nucleus at the meso position. Meanwhile, the acetylene fragment in the propynyl bridge at the $\mathrm{C}-2$ atom of the pyrrole ring increased the $\pi$-electronic delocalization of BODIPY-backbone in compounds 25 and 26. Consequently, conjugates 25 and 26 demonstrated a significant bathochromic shift of the absorption maximum $\left(25, \lambda_{\text {abs }} 551 \mathrm{~nm}\right)$ and the luminescence maximum $\left(\lambda_{\mathrm{em}} 578 \mathrm{~nm}\right)$ relative to BODIPY $\left(\lambda_{\mathrm{em}} 518 \mathrm{~nm}\right)$. Moreover, compared to the initial substances, iodine derivatives of BODIPY 19 and 20, conjugates 25 and 26 exhibited an 
increase in quantum yields and Stokes shifts. We believe that the novel approach developed by our research group can find application in the synthesis of BODIPY-triterpenoid conjugates as potential fluorescent probes for biological studies of triterpene compounds.

\begin{abstract}
Author Contributions: Validation and writing - review and editing, A.S.; performing the chemistry experiments, R.G. and E.D.; performing the photoluminescent (PL) experiments, A.T. The manuscript was prepared through the contributions of A.S., R.G., and D.N. All authors have read and agreed to the published version of the manuscript.
\end{abstract}

Funding: This research was funded by RUSSIAN SCIENCE FOUNDATION, grant number 19-7300155.

Acknowledgments: The structural studies of the synthesized compounds were performed with the use of Collective Usage Centre "Agidel" at the Institute of Petrochemistry and Catalysis of RAS.

Conflicts of Interest: The authors declare no conflict of interest.

\title{
References
}

1. Dzubak, P.; Hajduch, M.; Vydra, D.; Hustova, A.; Kvasnica, M.; Biedermann, D.; Markova, L.; Urban, M.; Sarek, J. Pharmacological activities of natural triterpenoids and their therapeutic implications. Nat. Prod. Rep. 2006, 23, $394-411$.

2. Mullauer, F.B.; Kessler, J.H.; Medema, J.P. Betulinic acid, a natural compound with potent anticancer effects. Anticancer Drugs 2010, 21, 215-227.

3. Sheng, H.; Sun, H. Synthesis, biology and clinical significance of pentacyclic triterpenes: A multi-target approach to prevention and treatment of metabolic and vascular diseases. Nat. Prod. Rep. 2011, 28, 543-593.

4. Cichewicz, R.H.; Kouzi, S.A. Chemistry, biological activity, and chemotherapeutic potential of betulinic acid for the prevention and treatment of cancer and HIV infection. Med. Res. Rev. 2004, 24, 90-114.

5. Csuk, R. Betulinic acid and its derivatives: A patent review (2008-2013). Expert Opin. Ther. Pat. 2014, 24, 913-923.

6. Kashiwada, Y.; Hashimoto, F.; Cosentino, L.M.; Chen, C.-H.; Garrett, P.E.; Lee, K.-H. Betulinic Acid and Dihydrobetulinic Acid Derivatives as Potent Anti-HIV Agents. J. Med. Chem. 1996, 39, 1016-1017.

7. AIKEN, C.; CHEN, C. Betulinic acid derivatives as HIV-1 antivirals. Trends Mol. Med. 2005, 11, 31-36.

8. Martin, D.E.; Salzwedel, K.; Allaway, G.P. Bevirimat: A novel maturation inhibitor for the treatment of HIV-1 infection. Antivir. Chem. Chemother. 2008, 19, 107-113.

9. Yu, D.; Wild, C.T.; Martin, D.E.; Morris-Natschke, S.L.; Chen, C.-H.; Allaway, G.P.; Lee, K.-H. The discovery of a class of novel HIV-1 maturation inhibitors and their potential in the therapy of HIV. Expert Opin. Investig. Drugs 2005, 14, 681-693.

10. Nedopekina, D.A.; Gubaidullin, R.R.; Odinokov, V.N.; Maximchik, P.V.; Zhivotovsky, B.; Bel'Skii, Y.P.; Khazanov, V.A.; Manuylova, A.V.; Gogvadze, V.; Spivak, A.Y. Mitochondria-targeted betulinic and ursolic acid derivatives: Synthesis and anticancer activity. MedChem Comm 2017, 8, 1934-1945.

11. Spivak, A.Y.; Nedopekina, D.A.; Khalitova, R.R.; Gubaidullin, R.R.; Odinokov, V.N.; Bel'skii, Y.P.; Bel'skaya, N.V.; Khazanov, V.A. Triphenylphosphonium cations of betulinic acid derivatives: Synthesis and antitumor activity. Med. Chem. Res. 2017, 26, 518-531.

12. Tsepaeva, O.V.; Nemtarev, A.V.; Abdullin, T.I.; Grigor'Eva, L.R.; Kuznetsova, E.V.; Akhmadishina, R.A.; Ziganshina, L.E.; Cong, H.H.; Mironov, V.F. Design, Synthesis, and Cancer Cell Growth Inhibitory Activity of Triphenylphosphonium Derivatives of the Triterpenoid Betulin. J. Nat. Prod. 2017, 80, 2232-2239.

13. Sommerwerk, S.; Heller, L.; Kerzig, C.; Kramell, A.E.; Csuk, R. Rhodamine B conjugates of triterpenoic acids are cytotoxic mitocans even at nanomolar concentrations. Eur. J. Med. Chem. 2017, 127, 1-9.

14. Wolfram, R.K.; Heller, L.; Csuk, R. Targeting mitochondria: Esters of rhodamine B with triterpenoids are mitocanic triggers of apoptosis. Eur. J. Med. Chem. 2018, 152, 21-30.

15. Fulda, S.; Kroemer, G. Targeting mitochondrial apoptosis by betulinic acid in human cancers. Drug Discov. Today 2009, 14, 885890.

16. Fulda, S.; Kroemer, G. Mitochondria as Therapeutic Targets for the Treatment of Malignant Disease. Antioxid. Redox Signal. 2011, 15, 2937-2949.

17. Zhang, X.; Hu, J.; Chen, Y. Betulinic acid and the pharmacological effects of tumor suppression (Review). Mol. Med. Rep. 2016, 14, 4489-4495.

18. Bertrand, B.; Passador, K.; Goze, C.; Denat, F.; Bodio, E.; Salmain, M. Metal-based BODIPY derivatives as multimodal tools for life sciences. Coord. Chem. Rev. 2018, 358, 108-124.

19. Boens, N.; Leen, V.; Dehaen, W. Fluorescent indicators based on BODIPY. Chem. Soc. Rev. 2012, 41, 1130-1172.

20. Karolin, J.; Johansson, L.B.-A.; Strandberg, L.; Ny, T. Fluorescence and Absorption Spectroscopic Properties of Dipyrrometheneboron Difluoride (BODIPY) Derivatives in Liquids, Lipid Membranes, and Proteins. J. Am. Chem. Soc. 1994, 116, 78017806.

21. Bañuelos, J. BODIPY Dye, the Most Versatile Fluorophore Ever? Chem. Rec. 2016, 16, 335-348. 
22. Martinez-Gonzalez, M.R.; Urías-Benavides, A.; Alvarado-Martínez, E.; Lopez, J.C.; Gómez, A.M.; del Rio, M.; Garcia, I.; Costela, A.; Bañuelos, J.; Arbeloa, T.; et al. Convenient Access to Carbohydrate-BODIPY Hybrids by Two Complementary Methods Involving One-Pot Assembly of "Clickable" BODIPY Dyes. Eur. J. Org. Chem. 2014, 2014, 5659-5663.

23. Králová, J.; Jurášek, M.; Krčová, L.; Dolenský, B.; Novotný, I.; Dušek, M.; Rottnerová, Z.; Kahle, M.; Drašar, P.; Bartůněk, P.; et al. Heterocyclic sterol probes for live monitoring of sterol trafficking and lysosomal storage disorders. Sci. Rep. 2018, 8, 1-11.

24. Osati, S.; Ali, H.; van Lier, J.E. BODIPY-steroid conjugates: Syntheses and biological applications. J. Porphyr. Phthalocyanines 2016, 20, 61-75.

25. Hanson, R.N.; Gajadeera, N. Design and synthesis of fluorescently labeled steroidal antiestrogens. Steroids 2019, $145,39-46$.

26. Li, Z.; Mintzer, E.; Bittman, R. First Synthesis of Free Cholesterol-BODIPY Conjugates. J. Org. Chem. 2006, 71, $1718-1721$.

27. Bacsa, I.; Konc, C.; Orosz, A.; Kecskeméti, G.; Rigó, R.; Özvegy-Laczka, C.; Mernyák, E. Synthesis of Novel C-2- or C-15-Labeled BODIPY - Estrone Conjugates. Molecules 2018, 23, 821.

28. Malachowska-Ugarte, M.; Sperduto, C.; Ermolovich, Y.V.; Sauchuk, A.L.; Jurášek, M.; Litvinovskaya, R.P.; Straltsova, D.; Smolich, I.; Zhabinskii, V.N.; Drašar, P.; et al. Brassinosteroid-BODIPY conjugates: Design, synthesis, and properties. Steroids 2015, 102, 53-59.

29. Krajcovicova, S.; Stankova, J.; Dzubak, P.; Hajduch, M.; Soural, M.; Urban, M. A Synthetic Approach for the Rapid Preparation of BODIPY Conjugates and their use in Imaging of Cellular Drug Uptake and Distribution. Chemistry 2018, 24, 4957-4966.

30. Brandes, B.; Hoenke, S.; Fischer, L.; Csuk, R. Design, synthesis and cytotoxicity of BODIPY FL labelled triterpenoids. Eur. J. Med. Chem. 2020, 185, 111858.

31. Spivak, A.Y.; Gubaidullin, R.R.; Galimshina, Z.R.; Nedopekina, D.A.; Odinokov, V.N. Effective synthesis of novel C(2)-propargyl derivatives of betulinic and ursolic acids and their conjugation with $\beta$-d-glucopyranoside azides via click chemistry. Tetrahedron 2016, 72, 1249-1256.

32. Gubaidullin, R.R.; Yarmukhametova, D.S.; Nedopekina, D.A.; Khalitova, R.R.; Spivak, A.Y. Effective synthesis of novel furanfused pentacyclic triterpenoids via anionic 5-exo dig cyclization of 2-alkynyl-3-oxotriterpene acids. Arkivoc 2017, 2017, $100-116$.

33. Gubaidullin, R.R.; Khalitova, R.R.; Galimshina, Z.R.; Spivak, A.Y. Synthesis of novel [3,2-b] furan-fused pentacyclic triterpenoids via gold-Catalyzed intramolecular heterocyclization of 2-alkynyl-3-oxotriterpene acids. Tetrahedron 2018, 74, 1888-1899.

34. Kim, D.S.; Chen, Z.; Nguyen, V.T.; Pezzuto, J.M.; Qiu, S.; Lu, Z.Z. A Concise Semi-Synthetic Approach to Betulinic Acid from Betulin. Synth. Commun. 1997, 27, 1607-1612.

35. Xie, Y.; Zhang, F.; Liu, P.; Hao, F.; Luo, H. Synthesis and catalytic properties of trans-A2B2-type metalloporphyrins in cyclohexane oxidation. Can. J. Chem. 2013, 92, 49-53.

36. Basumatary, B.; Raja Sekhar, A.; Ramana Reddy, R.V.; Sankar, J. Corrole-BODIPY Dyads: Synthesis, Structure, and Electrochemical and Photophysical Properties. Inorg. Chem. 2015, 54, 4257-4267.

37. Ortiz, M.J.; Agarrabeitia, A.R.; Duran-Sampedro, G.; Bañuelos Prieto, J.; Lopez, T.A.; Massad, W.A.; Montejano, H.A.; García, N.A.; Lopez Arbeloa, I. Synthesis and functionalization of new polyhalogenated BODIPY dyes. Study of their photophysical properties and singlet oxygen generation. Tetrahedron 2012, 68, 1153-1162.

38. Loudet, A.; Burgess, K. BODIPY Dyes and Their Derivatives: Syntheses and Spectroscopic Properties. Chem. Rev. 2007, 107, 4891-4932.

39. Zhang, D.; Wang, Y.; Xiao, Y.; Qian, S.; Qian, X. Long-wavelength boradiazaindacene derivatives with two-photon absorption activity and strong emission: Versatile candidates for biological imaging applications. Tetrahedron 2009, 65, 8099-8103.

40. Kolemen, S.; Bozdemir, O.A.; Cakmak, Y.; Barin, G.; Erten-Ela, S.; Marszalek, M.; Yum, J.-H.; Zakeeruddin, S.M.; Nazeeruddin, M.K.; Grätzel, M.; et al. Optimization of distyryl-Bodipy chromophores for efficient panchromatic sensitization in dye sensitized solar cells. Chem. Sci. 2011, 2, 949-954.

41. Leen, V.; Leemans, T.; Boens, N.; Dehaen, W. 2- and 3-Monohalogenated BODIPY Dyes and Their Functionalized Analogues: Synthesis and Spectroscopy. Eur. J. Org. Chem. 2011, 2011, 4386-4396.

42. Qin, W.; Rohand, T.; Dehaen, W.; Clifford, J.N.; Driesen, K.; Beljonne, D.; Van Averbeke, B.; Van der Auweraer, M.; Boens, N. Boron Dipyrromethene Analogs with Phenyl, Styryl, and Ethynylphenyl Substituents: Synthesis, Photophysics, Electrochemistry, and Quantum-Chemical Calculations. J. Phys. Chem. A 2007, 111, 8588-8597. 